\title{
A Novel Multi-Functional DSTATCOM with Distribution Generation using FRC Controller
}

\author{
CH. Sri Prakash ${ }^{1}$, G. Kesava Rao ${ }^{2}$, O. Chandrasekhar ${ }^{3}$, P. V. Satyaramesh ${ }^{4}$ \\ ${ }_{1,2,3}$ Department of Electrical \& Electronics Engineering, KL University, Vaddeswaram, \\ Guntur (Dt), Andhra Pradesh, India \\ ${ }^{4}$ APTRANSCO, Hyderabad, Telangana, India
}

\begin{tabular}{l} 
Article Info \\
\hline Article history: \\
Received Jan 12, 2018 \\
Revised Mar 15, 2018 \\
Accepted Mar 29, 2018 \\
\hline
\end{tabular}

Keyword:

Distributed generation Multi-functional DSTATCOM

Photo-voltaic system

Power-quality improvement

Renewable energy generation

\begin{abstract}
Distribution Generation plays a significant role in remote areas where the utility grid is affected and initializing by renewable energy sources to acquire the sufficient power demand. In distribution system, it is very exigent consumer related concern which is confronted due to mis-operation of massive non-linear load apparatus. A multi-functional distributed static compensator incorporates the best choice for enhancing the power quality features with effective control scheme under rambled non-linear loads. Conventional control schemes are more adversed with greater switching losses due to extreme harmonic frequencies in a refernce current component. This paper proposes, a novel multi-objective fundamental reference current control scheme based multi-functional DSTATCOM furnishes the current harmonic compensation at $\mathrm{PCC}$, reactive power compensation, power factor correction, active power exchanging, minimizing the switching losses, incredible efficiency and power factor correction. The validation of proposed multi-functional DSTATCOM with proposed control strategy under rated capacity of distribution generation is evaluated by using Matlab/Simulink platform and simulation results are presented.
\end{abstract}

Copyright $@ 2018$ Institute of Advanced Engineering and Science. All rights reserved.

\section{Corresponding Author:}

CH. Sri Prakash,

Department of Electrical and Electronics Engineering,

KL University,

Vaddeswaram, Guntur (Dt), Andhra Pradesh, India.

Email: sriprakash670@gmail.com

\section{INTRODUCTION}

Utilization of electrical energy is highly intensified by many leaps and bounds so as to enhance the standard living at recent days. The eminent inspiration is required for production of reliable energy with respect to decent standard prominences. Distribution Generation (DG) has tremendous development because of incredible energy demand, fossil fuels reduction, and clean energy by utilizing Renewable Energy Sources (RES) [1]. Various renewable sources are Solar-Photo Voltaic (SPV) cells; Fuel Cells (FC) stacks and Wind Energy Systems (WES) are integrated to PCC at distribution system by using power conditioning units. Power Quality (PQ) is the major concern in a traditional distribution system due to presence of non-linear characteristics of power semi-conductor apparatus. Non-linear load apparatus stimulus the effective harmonic current sequences with non-unity power factor, which establishes the vital obstacles at point of common coupling (PCC) [2].

In near future electrical energy will be a commodity which is marketed by judging the quality terms in a contention field. Formal PQ enhancement schemes are accessible in former days by consisting of passive filter units, which are interfaced to the PCC or load as parallel or series formation. Various disadvantages are illustrated in [3], like fixed compensation principle, low response, resonance issues and massive size, etc. Novel progressive custom power devices based active compensation schemes are utilized for PQ 
enhancement [4]. The novel active conditioning scheme plays a vital role in power distribution systems comprising of voltage source inverter (VSI). The VSI compensation scheme is the best choice and integrated as shunt topology at PCC level to eradicate the current harmonics and enhance the power quality. In distribution system [5], it acts as a distributed static compensation (DSTATCOM) to compensate the current related concerns such as eradication of current harmonics, reactive power compensation, active power control, unbalanced loading effect, power factor correction, etc. The basic structure of an DSTATCOM is akin to that of a DG inverter, the DG inverter may not functioning at its rated capacity at all time because of stochastic nature of the renewable energy. If controlled uniquely, the unused energy of DG system can be prominently used for furnishing ancillary services, such that compensation is noted as multi-functional DSTATCOM.

The proposed MF-DSTATCOM minimizes the necessity of additional compensation devices and reduces the over-all cost of the compensation; it may increase the power demand, etc. The main objective of proposed MF-DSTATCOM injects the related harmonic sequences of distorted current which is effectively maintaining the PCC voltage as a constant. As well as exchanging the active/reactive power when any shortcomings acquired from load apparatus by utilizing effective control objective. Such that harmonic distortions, unbalanced short-comings, active/reactive power exchanging are the major concerns which are easily transformed into equivalent resistive balanced system by using multi-functional DSTATCOM [6]. Effective control scheme generates the optimal switching signals, to achieve the definite compensation task which performs the proper functioning of the proposed MF-DSTATCOM [7], [8]. Various control schemes are reviewed by several literatures, such as symmetrical power theory [9], synchronous reference frame theory [10], instantaneous real power theory [11], etc. The traditional control schemes provides switching signals to DSTATCOM at very high switching frequencies, which makes high switching stress, increased losses and minimizing the over-all compensation efficiency. A dual control strategy is needed for DG operation and active compensation task, which increase the complexity, size, cost, etc.

This paper proposes the novel control scheme for both DG operation and PQ enhancement features in distribution system which furnishes the multi-functional DSTATCOM. The modified fundamental reference id-iq control scheme is implemented to extract the superlative reference current signal which overcomes the additional DG controller and several problems attained from traditional control objectives. The proposed novel control objective based three phase MF-DSTATCOM is validated in both DG operation and power quality enhancement with the help of Matlab/Simulink tool and simulation results are conferred which evaluates the attractiveness of proposed control scheme

\section{MULTI-FUNCTIONAL DSTATCOM}

The DSTATCOM also known as distributed static compensator is mainly integrated in distribution system to enhance the PQ features. It comprises of three phase VSI, DC-link capacitor, control scheme, gate drive strategy, LC filter units, etc., [12]. Generally VSI's acts as the active compensation device especially to eradicate the harmonics coming from non-linear load and also used as interfacing converter in several DG units. This VSI topology operates in current control mode during harmonic compensation at PCC as well as operates in voltage controlled mode in DG scheme to supply active/reactive power to the load. In DG scheme, an additional source is requires normally battery energy system is utilized but it requires additional energy management schemes [13].

A renewable energy plays a prominent role in DG operation over the battery system, in that PV system plays a mature energy generation scheme. The circuit configuration of proposed MF-DSTATCOM with PV scheme is interfaced at PCC in distribution system as depicted in Figure 1. The elements $\mathrm{V}_{\text {sabc }}, \mathrm{V}_{\text {Labc }}$, $I_{\text {sabc }}, I_{\text {Labc }}$, and $Z_{\text {sabc }}$ are three phase source voltage, load voltage, source current, load current and source impedance respectively. The load treated as non-linear type diode-bridge rectifier supported as balanced RLload system [14]. The PV generation scheme acts as main source of VSI which is integrated to DC-link capacitor $\mathrm{C}_{\mathrm{dc}}$ by utilizing the DC-DC converter, which transforms the low level DC voltage to high DC voltage and maintains DC-link voltage $\mathrm{V}_{\mathrm{dc}}$ as a constant. Significant LC filter units are associated at frontend of the VSI to regulate the standard voltage and proper compensation characteristics at PCC level.

The performance of the MF-DSTATCOM is well defined based on active-filtering technique and DG operation by using proposed control scheme. It is immensely required for riddling the harmonic compensation, so as to obtain the optimal in-phase compensation principle. It administers the MFDSTATCOM currents at PCC for appropriate harmonic eradication, reactive power exchanging, power factor correction, etc [15]-[18]. Provoking the in-phase current injection processes with exchanging active-reactive power is possible by utilizing control scheme. Several control schemes are studied; in that synchronous reference frame Id-Iq theory is prominently used for generation of refernce current sequences. But, it has high switching frequency, which influences the high switch stress, greater switching losses, accomplishes the 
un-speculated efficiency. The related concerns are overcome by proposed fundamental frequency based reference current generation scheme, generates the switching states at fundamental frequency which minimizes the switch stress, minimizes the losses and attaining the incredible efficiency.

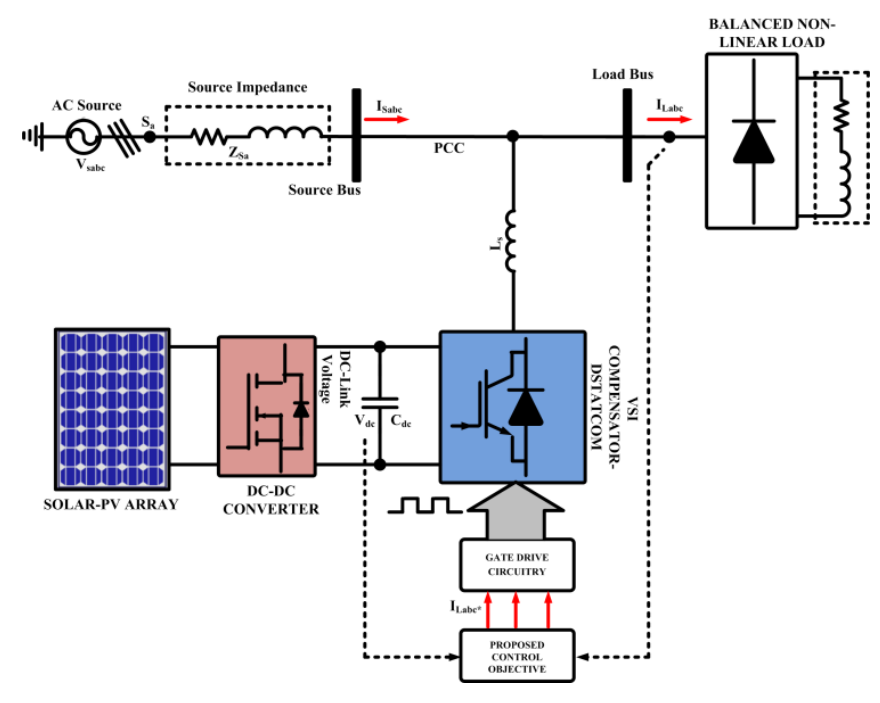

Figure 1. The Circuit Configuration of Proposed PV Based MF-DSTATCOM Compensation Scheme

\section{PROPOSED FUNDAMENTAL FREQUENCY BASED Id-Iq CONTROL THEORY}

The evaluation of proposed fundamental reference frequency (FRC) based $I_{d}-I_{q}$ technique is generally developed by classical $\mathrm{I}_{\mathrm{d}}-\mathrm{I}_{\mathrm{q}}$ theory based on instantaneous active/reactive current integrants with the favour of desired current component furnished from the load apparatus. A double transformation processes is provoked by optimum inter-relation between the stationary and rotating reference switching sequences. At first the phase quantities of load current $\left(I_{L a b c}\right)$ is transformed into stationary frame methodology $\left(I_{L \alpha}-I_{L \beta}\right)$ by using Clarke's transformation process and the rotating frame sequences as direct/quadrature axis of load currents $\left(\mathrm{I}_{\mathrm{Ld}}, \mathrm{I}_{\mathrm{Lq}}\right)$ components are positioned from the stationary reference frame technique by utilizing Park's transformation by utilizing the angle $(\theta)$. The coming transformation sequences of three phases to two-phase quantities as illustrated in Equations (1), (2) and (3) are applied to certain phase sequences.

$$
\begin{aligned}
& {\left[\begin{array}{l}
i_{L d} \\
i_{L q}
\end{array}\right]=\frac{2}{3}\left[\begin{array}{ccc}
\cos (\theta) & \cos \left(\theta-\frac{2 \pi}{3}\right) & \cos \left(\theta+\frac{2 \pi}{3}\right) \\
\sin (\theta) & \sin \left(\theta-\frac{2 \pi}{3}\right) & \sin \left(\theta+\frac{2 \pi}{3}\right)
\end{array}\right]\left[\begin{array}{l}
i_{L a} \\
i_{L b} \\
i_{L c}
\end{array}\right]} \\
& {\left[\begin{array}{l}
i_{\alpha} \\
i_{\beta}
\end{array}\right]=\frac{2}{3}\left[\begin{array}{ccc}
1 & -1 / 2 & -1 / 2 \\
0 & \sqrt{3} / 2 & -\sqrt{3} / 2
\end{array}\right]\left[\begin{array}{l}
i_{L a} \\
i_{L b} \\
i_{L c}
\end{array}\right]} \\
& {\left[\begin{array}{l}
i_{L d} \\
i_{L q}
\end{array}\right]=\left[\begin{array}{cc}
\cos \omega t & \sin \omega t \\
-\sin \omega t & \cos \omega t
\end{array}\right]\left[\begin{array}{l}
i_{\alpha} \\
i_{\beta}
\end{array}\right]} \\
& {\left[\begin{array}{l}
i_{L d} \\
i_{L q}
\end{array}\right]=\left[\begin{array}{c}
\overline{l_{L d}}+\widetilde{l_{L d}} \\
\overline{l_{L q}}+\widetilde{\iota_{L q}}
\end{array}\right]} \\
& {\left[\begin{array}{l}
i_{L d} \\
i_{L q}
\end{array}\right]=\left[\begin{array}{c}
\overline{l_{L d}}+\widetilde{\imath_{L d}} \\
0
\end{array}\right]}
\end{aligned}
$$

Where, $\overline{l_{L d}} \& \widetilde{\imath_{L d}}$ constitutes the DC-AC components of load current on d-q frame, the respective two-axis load current components on regular d-q frame is illustrated in Equation (4). In proposed Id-Iq control theory, the q-component is established as zero (0) illustrated in Equation (5). It should be represented as d-q 
sequences comprising of single term $\widetilde{\tau_{L d}}$ and utilizing low-pass filter to distinct the fundamental frequency of $\widetilde{l_{L d}}$ integrant with suitable cut-off frequency. The DC-link controller is mainly recruited to sustain the DClink voltage as constant for attaining the optimal compensation principle by employing the PI controller. This controller minimizes the error quantities for measuring the precise value of $\mathrm{PL}_{\mathrm{oss}}$ by comparison of reference DC-link voltage $\left(\mathrm{V}_{\mathrm{dcref}}\right)$ and actual DC-link voltages $\left(\mathrm{V}_{\text {dcact }}\right)$ as shown in Equation $(6)$.

$$
V_{\text {dcerr }}=V_{d c r e f}^{*}-V_{\text {dcact }}
$$

The DG system will support extensive active power to load apparatus in remote locations as well as sustain the capability of load sharing between the utility system and PCC/grid system using RES. In that, PV system plays a major role in DG energy management system, a single PV cell is determined based on semiconductor material for small voltage potential generation. The model of PV cell is consisted of diode, controlled current source, shunt-series resistances, to generate voltage potential at output nodes. The mathematical model of the PV cell is illustrated in over-all diagram Figure 2.

$$
I_{p v r e f}=I_{p v}-I_{s v}\left[\exp q^{\frac{\left(V_{p v+R} R_{v I^{*}}\right)}{N K T}}\right]-1-\left[\frac{V_{p v}+R_{S v} * I_{v}}{R_{S h v}}\right]
$$

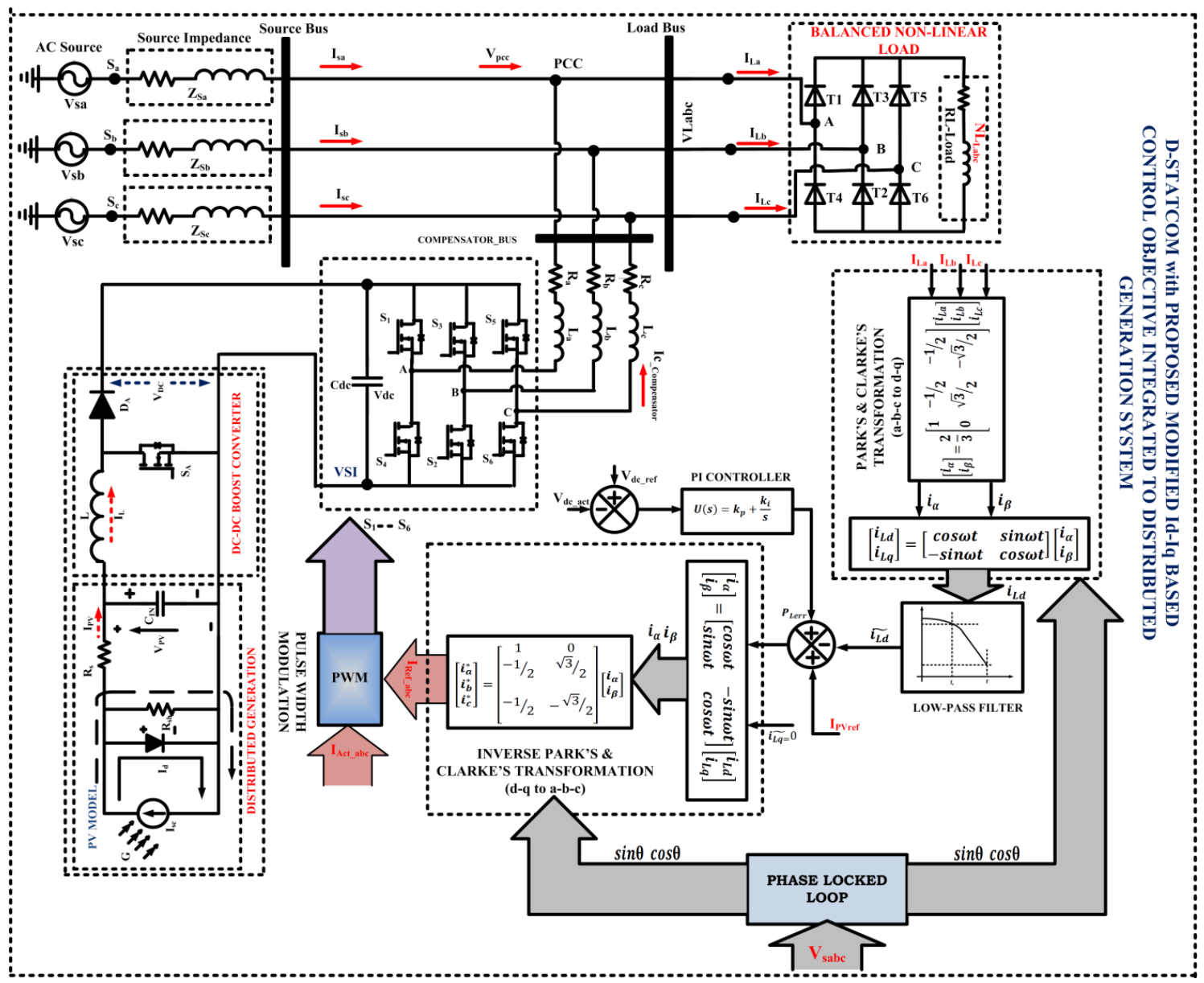

Figure 2. Over-all Schematic Diagram of Proposed Fundamental Frequency Id-Iq Control Theory Fed MFDSTATCOM

Based on circuit model, the current is transferred to load via controlled current source; it can be established in, Equation (7). It defines the current equation of single PV cell, the output of the PV cell resulting the physical attraction of the PV cell which is relating with, $I_{s v}, I_{p v}$, and $R_{s v}$, from the irradiation and temperature over the other. Where-as, $I_{p v}$ is the photo-voltaic current, $I_{s v}$ is reverse saturation current of 
diode, $V_{p v}$ is node voltage of diode, $\mathrm{K}$ is Boltzmann's constant, $\mathrm{q}$ is electron charge, $\mathrm{T}$ is junction temperature, $\mathrm{N}$ is ideal index factor, $R_{s h v}$ is shunt resistance and $R_{s v}$ is series resistance of PV cell respectively. The final refernce current signal is extracted based on summation of $I_{\text {pvref }}, \mathrm{P}_{\text {Lerr }}$ component and active fundamental $i_{L d}$ component for active compensation of PQ features and DG operation in three phase distribution system as shown in Equation (8).

$$
\left[\begin{array}{l}
i_{L d} \\
i_{L q}
\end{array}\right]=\left[\begin{array}{c}
\overline{\iota_{L d}}+\widetilde{\iota_{L d}} \\
0
\end{array}\right]+\text { PLerr }+I_{\text {pvref }}
$$

Substitute Equation (7) in Equation (8), the outcome reference current in d-q frame is shown in Equation (9),

$$
\begin{aligned}
& {\left[\begin{array}{l}
i_{L d} \\
i_{L q}
\end{array}\right]=\left[\begin{array}{c}
\overline{\iota_{L d}}+\widetilde{\iota_{L d}} \\
0
\end{array}\right]+\text { PLerr }+I_{p v}-I_{s v}\left[\exp q^{\frac{\left(V_{p v+R} R_{S v} * I_{v}\right)}{N K T}}\right]-1-\left[\frac{V_{p v}+R_{S v} * I_{v}}{R_{S h v}}\right]} \\
& {\left[\begin{array}{l}
i_{\alpha} \\
i_{\beta}
\end{array}\right]=\left[\begin{array}{cc}
\cos \omega t & -\sin \omega t \\
\sin \omega t & \cos \omega t
\end{array}\right]\left[\begin{array}{l}
i_{L d} \\
i_{L q}
\end{array}\right]} \\
& {\left[\begin{array}{c}
i_{a}^{*} \\
i_{b}^{*} \\
i_{c}^{*}
\end{array}\right]=\left[\begin{array}{cc}
1 & 0 \\
-1 / 2 & \sqrt{3} / 2 \\
-1 / 2 & -\sqrt{3} / 2
\end{array}\right]\left[\begin{array}{l}
i_{\alpha} \\
i_{\beta}
\end{array}\right]}
\end{aligned}
$$

The coming fundamental refernce current sequence on d-frame $i_{L d}$ with $i_{L q}$ acts as zero which are re-transformed into actual three-phase refernce current quantities $\left(\mathrm{I}_{\mathrm{abc}}{ }^{*}\right)$ by engaging inverse transformation process as illustrated in Equation (10) and Equation (11). The reference current signal $\left(\mathrm{I}_{\mathrm{abc}}{ }^{*}\right)$ is compared to actual line currents for generation of optimal signal to provide the optimal switching states by using pulsewidth modulation technique to regulate the PQ features and DG operation, this proposed controller doesn't requires any additional control objectives to control the DG power while exchanging active/reactive power from distributed generation. The overall schematic diagram of fundamental reference current extraction based Id-Iq theory fed MF-DSTATCOM is depicted in Figure 2.

\section{RESULTS AND ANALYSIS}

The simulation analysis is conveyed by implementation of multi-functional distributed static compensation (MF-DSTATCOM) scheme in a three phase power distribution systems by using proposed

\begin{tabular}{|c|c|c|}
\hline S.No & Parameters & Values \\
\hline 1 & Source Voltage & $11 \mathrm{KV}$ \\
\hline 2 & Source Impedance & $0.1+\mathrm{j} 0.282 \Omega$ \\
\hline 3 & Load Impedance & $200+\mathrm{j} 37.6 \Omega$ \\
\hline 4 & DC-Link Capacitor & $1500 \mu \mathrm{F}$ \\
\hline 5 & VSI Filter Units & R-0.001; L-10mH \\
\hline 6 & PI Controller Gains & $\mathrm{Kp}-0.8 ; \mathrm{Ki}-0.5$ \\
\hline
\end{tabular}
fundamental frequency based reference current extraction Id-Iq theory under both DG operation and harmonic compensation scheme. Table 1 show the System Parameters of Proposed MF-DSTATCOM Scheme.

\subsection{Performance analysis of MF-DSTATCOM by using proposed control strategy under harmonic compensation}

Figure 3(a) to Figure 3(h) explores the steady state analysis of MF-DSTATCOM under harmonic compensation by using proposed control objective, in that (a) Source Voltage, (b) Source Current, (c) Compensation Current, (d) Load Current, (e) Source Voltage \& Current-In Phase Specifies the Unity Power Factor, (f) Load Voltage \& Current-In Phase Specifies the Unity Power Factor, (g) THD Analysis of Source Current, (h) THD Analysis of Load Current, respectively. The load treated as the non-linear load condition, due to this PCC current is highly harmonized under no compensation scheme and proliferate the power 
quality. The proposed MF-DSTATCOM compensates the harmonics and improves the power quality at PCC level. Due to proposed control objective, the source current maintains as harmonic-free response. Source voltage \& current is in-phase condition which represents the source power factor is unity and load power factor is non-unity due to non-linear loads. THD analysis of load current is $28.54 \%$ consisting of greater harmonic values and the THD analysis of source current is $3.63 \%$ consisting of low-harmonic well compensated by MF-DSTATCOM and well with in IEEE-519/1992 standards.

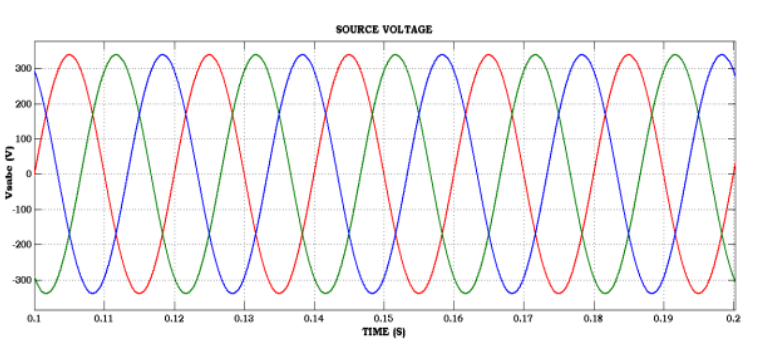

(a) Source Voltage

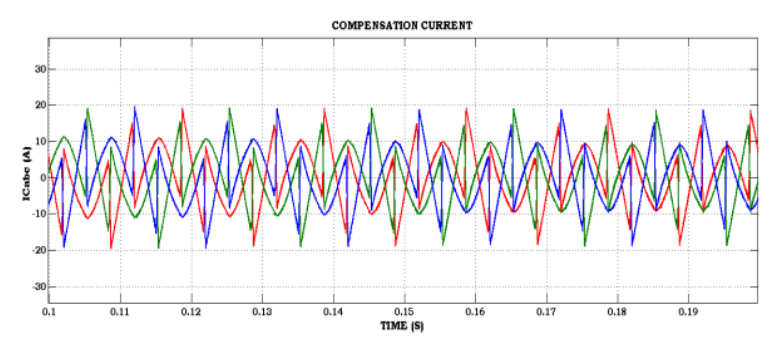

(c) Compensation Current

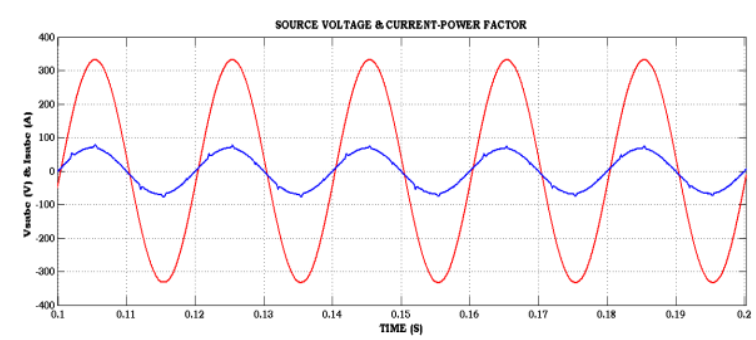

(e) Source Voltage \& Current Specifies the Unity Power Factor

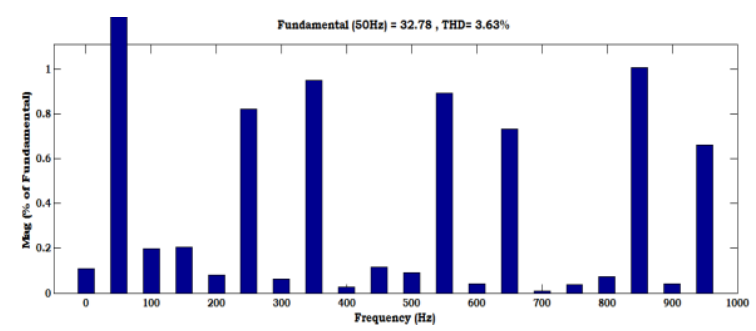

(g) THD Analysis of Source Current

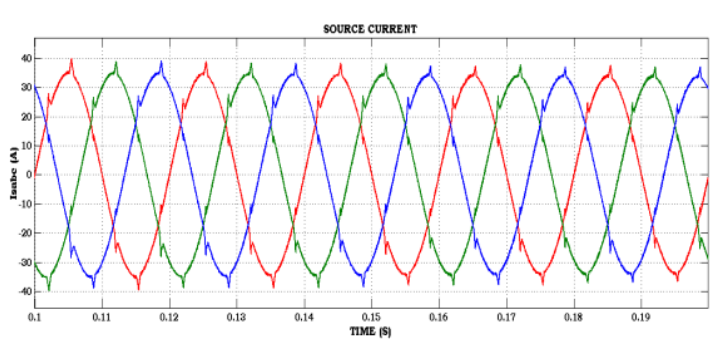

(b) Source Current

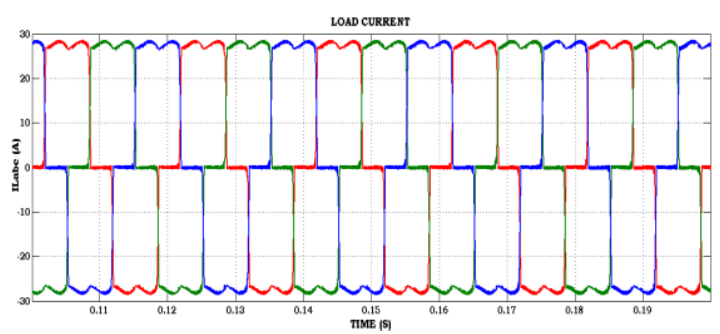

(d) Load Current

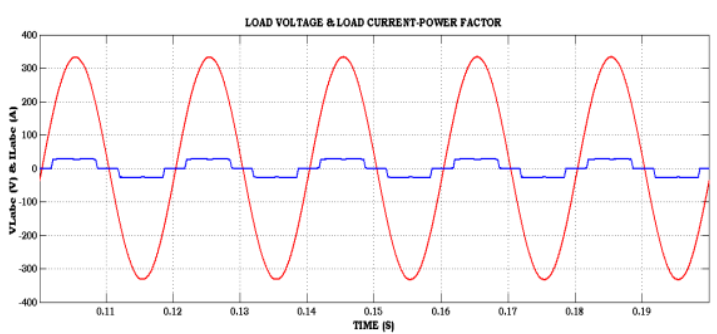

(f) Load Voltage \& Current Specifies the Non-Unity Power Factor

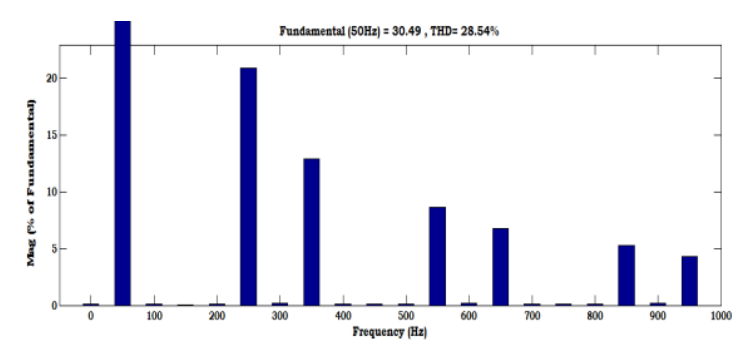

(h) THD Analysis of Load Current

Figure 3. Steady State Analysis of MF-DSTATCOM under Harmonic Compensation by using Proposed Control Objective

\subsection{Performance analysis of MF-DSTATCOM by using proposed control strategy under DG operation with $50 \%$ loading}

Figure 4(a) to Figure $4(\mathrm{k})$ explores the steady state analysis of MF-DSTATCOM under DG Operation of $50 \%$ loading by using proposed control objective, in that (a) Source Voltage, (b) Source Current, (c) Compensation Current, (d) Load Current, (e) Source Voltage \& Current-In Phase Specifies the Unity Power Factor, (f) Load Voltage \& Current-In Phase Specifies the Unity Power Factor, (g) Source 
Active Power, (h) Source Reactive Power, (i) Compensator Active Power, (j) Compensator Reactive Power, (k) PV-DG Current, respectively. Source voltage \& current is in-phase condition which represents the source power factor is unity and load power factor is non-unity due to non-linear loads. The DG system support PV energy to load and exchanging the reactive power and controlling the active power at load without any additional controller. This proposed controller generates the switching states to the MF-DSTATCOM under DG operation when requiring the $50 \%$ of the load active/reactive power. Based on requirement, the DG system supports energy to the load and maintains load voltage as a constant and obtaining the in-phase current injection processes.

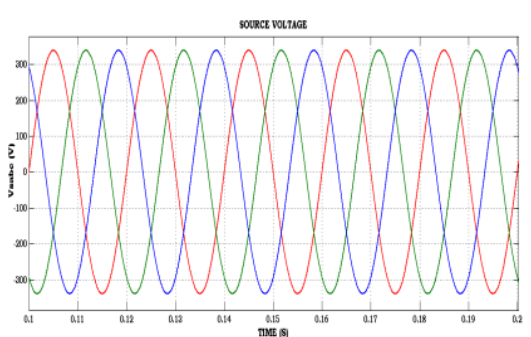

(a) Source Voltage

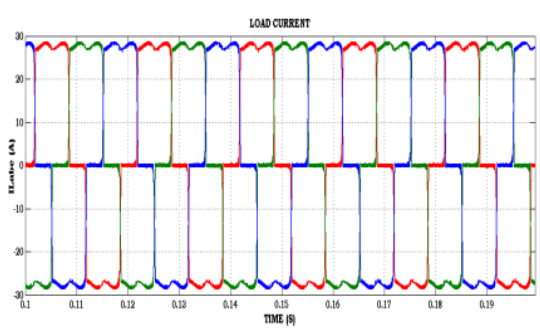

(d) Load Current

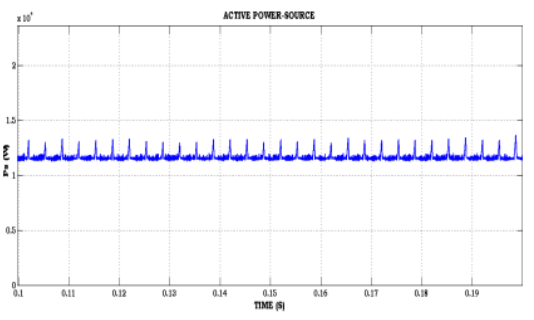

(g) Source Active Power

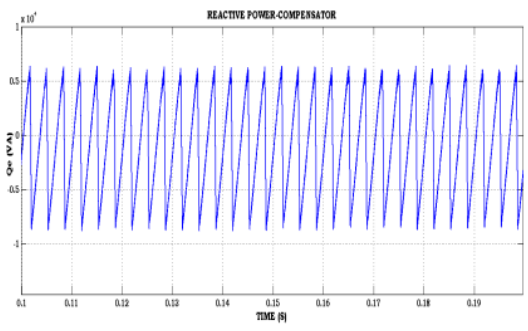

(j) Compensator Reactive Power

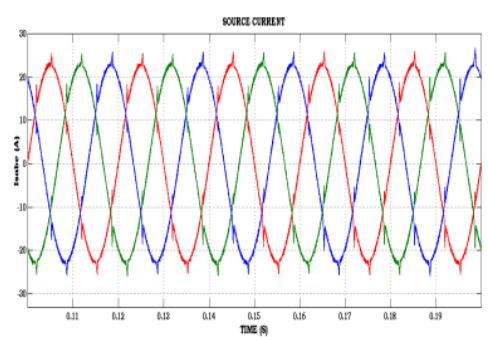

(b) Source Current

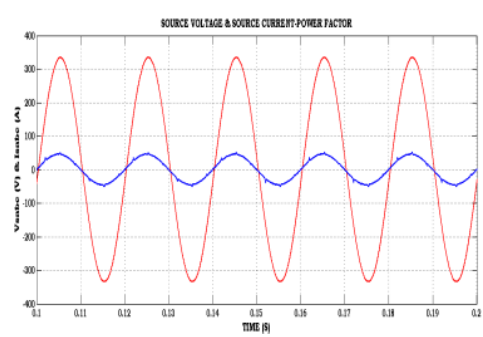

(e) Source Voltage \& Current Specifies the Unity Power Factor

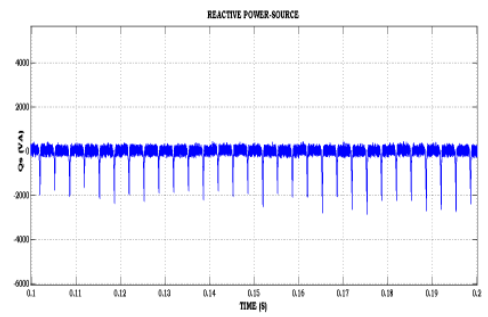

(h) Source Reactive Power

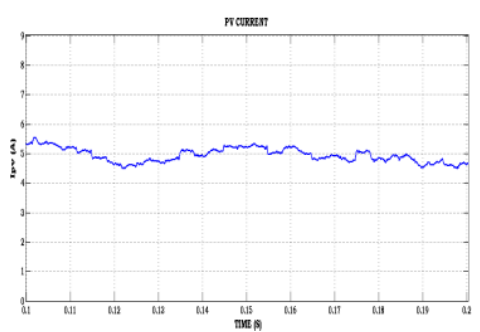

(k) PV-DG Current

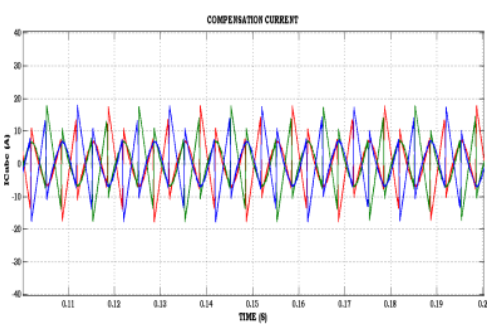

(c) Compensation Current

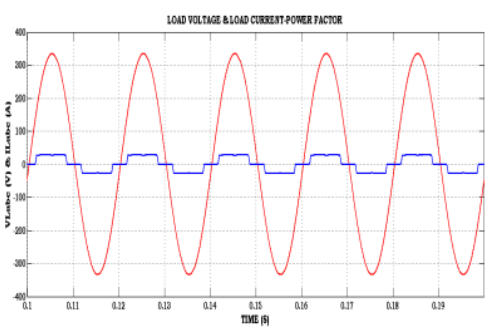

(f) Load Voltage \& Current Specifies the Non-Unity Power Factor

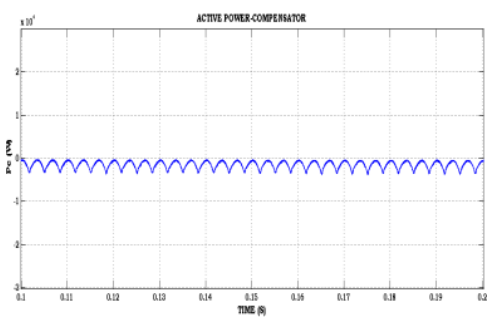

(i) Compensator Active Power

Figure 4. Steady State Analysis of MF-DSTATCOM under DG-Operation of 50\% loading by using Proposed Control Objective 
4.3. Performance analysis of MF-DSTATCOM by using proposed control strategy under DG operation with $100 \%$ loading

Figure 5(a) to Figure 5(e) explores the steady state analysis of MF-DSTATCOM under DG Operation of $100 \%$ loading by using proposed control objective, in that (a) Source Active Power, (b) Source Reactive Power, (c) Compensator Active Power, (d) Compensator Reactive Power, (e) PV-DG Current, respectively. The DG system support PV energy to load and exchanging the reactive power and controlling the active power at load without any additional controller. This proposed controller generates the switching states to the MF-DSTATCOM under DG operation when requiring the $100 \%$ of the load active/reactive power nothing but full-load controlling is achieving. Based on requirement, the DG system supports fullyrated energy to the load and maintains load voltage as a constant and obtaining the in-phase current injection processes.

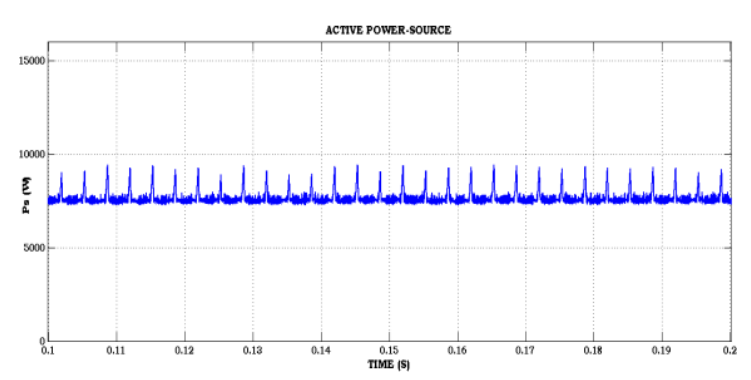

(a) Source Active Power

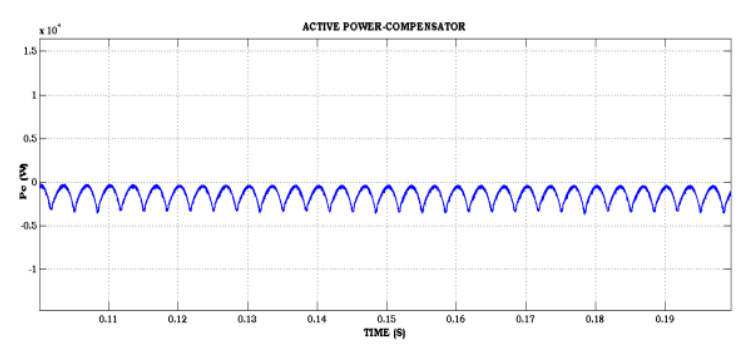

(c) Compensator Active Power

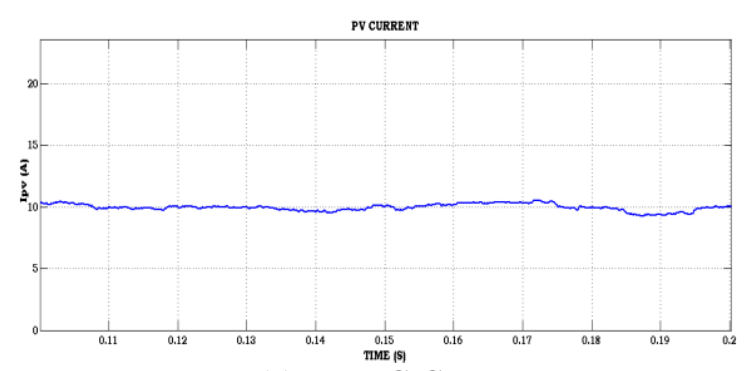

(e) PV-DG Current

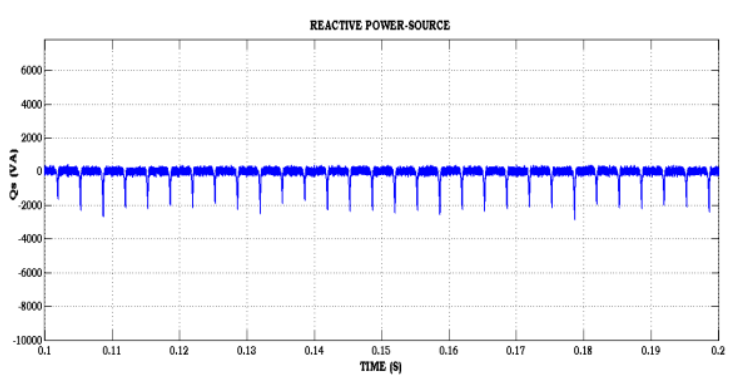

(b) Source Reactive Power

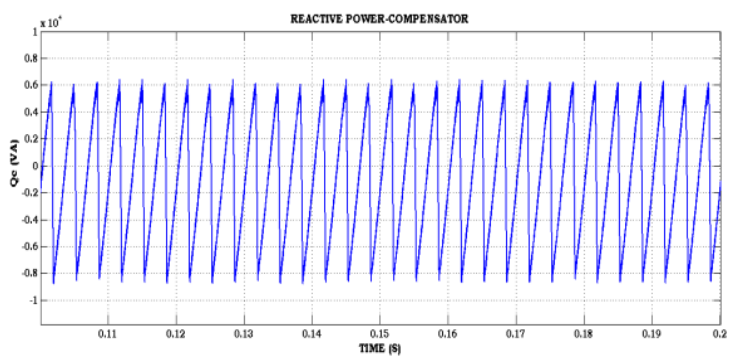

(d) Compensator Reactive Power

Figure 5. Steady State Analysis of MF-DSTATCOM under DG-Operation of $100 \%$ loading by using Proposed Control Objective

\subsection{Performance analysis of MF-DSTATCOM by using proposed control strategy under DG operation with $100 \%$ loading}

Figure 6(a) to Figure 6(k) explores the steady state analysis of MF-DSTATCOM under DG Operation with sudden power variation by using proposed control objective, in that (a) Source Voltage, (b) Source Current, (c) Compensation Current, (d) Load Current, (e) Source Active Power, (f) Source Reactive Power, (g) Compensator Active Power, (h) Compensator Reactive Power, (i) PV-DG Current, respectively. The DG system support PV energy to load and exchanging the reactive power and controlling the required active power at load without any additional controller. 
This proposed controller generates the switching states to the MF-DSTATCOM under DG operation when requiring the sudden variations in load active/reactive power. In this condition, sudden power variation is occurred at $0.2 \mathrm{sec}$; due to this PCC parameters are affected. Based on sudden load requirement, the DG system supports energy to the load and maintains load voltage as a constant and obtaining the in-phase current injection processes. As well as transforming the required active power to the load from DG without any additional control scheme. The proposed control strategy generates the specified DG-PV current to the load, maintains load active power and reactive as a constant and improves the power quality features at PCC level.

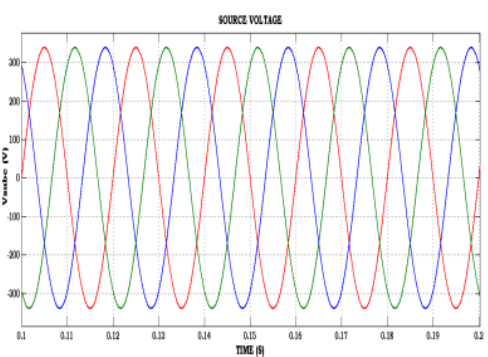

(a) Source Voltage

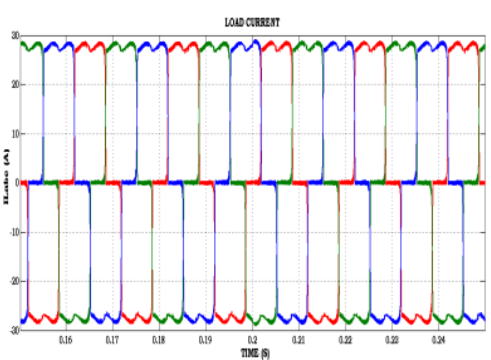

(d) Load Current

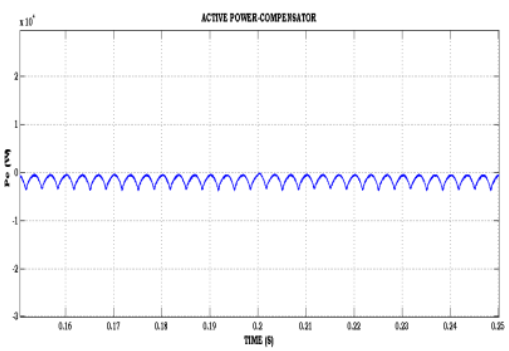

(g) Compensator Active Power

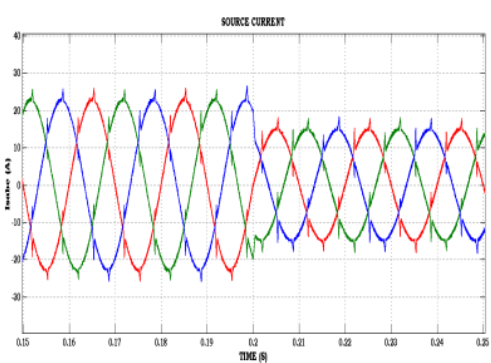

(b) Source Current

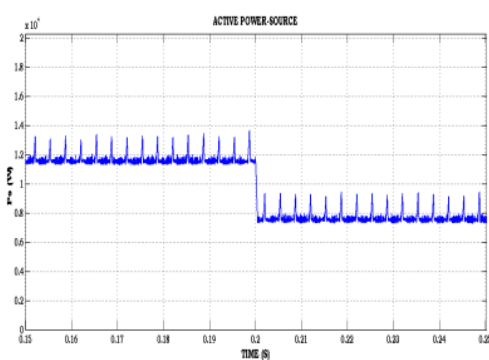

(e) Source Active Power

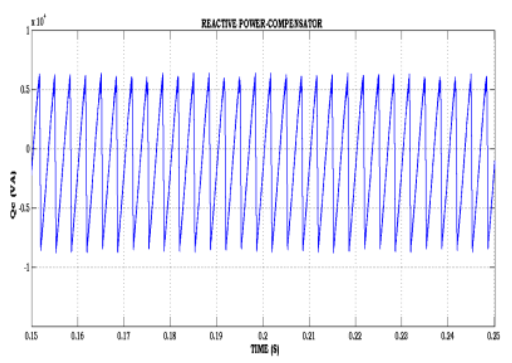

(h) Compensator Reactive Power

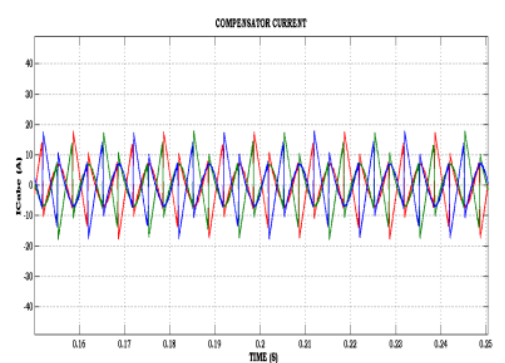

(c) Compensation Current

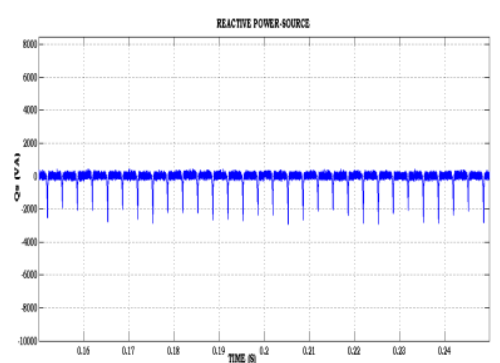

(f) Source Reactive Power

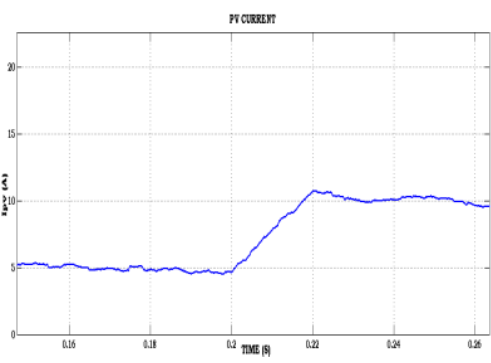

(i) PV-DG Current

Figure 6. Steady State Analysis of MF-DSTATCOM under DG-Operation with Sudden Power variation by using Proposed Control Objective

\section{CONCLUSION}

The proposed fundamental frequency based modified Id-Iq control scheme is highly validated for production of optimum in-phase compensation principle to enhance PQ features and DG operation. The proposed fundamental frequency based Id-Iq reference current generation scheme furnishes the optimal inphase compensation principle for dual purposes. Such as DG operation \& superior enhancement of power quality features at PCC level with reducing the switching losses and increasing the overall compensation efficiency. Without any additional controllers to control the DG-PV current under 50\%, 100\% loading and sudden power variations, to maintain PCC/load voltage as constant and increase the voltage stability and transforming the required active power to the load from DG system under constant \& variable loading conditions. The proposed control scheme generates the switching states in DG operations which reduces the use of additional control strategy components, low complexity, low space requirement, low cost, etc. The performance evaluation of proposed control objective to fed MF-DSTATCOM in a three phase power distribution system under is evaluated by using Matlab/Simulink tool and results are illustrated. The 
harmonic distortions at source current under harmonic compensation principle attains well with in IEEE-519 standards.

\section{REFERENCES}

[1] Y.S. Kim, E.S. Kim, and S.I. Moon, "Frequency and Voltage Control Strategy of Standalone Micro-Grids with High Penetration of Intermittent Renewable Generation Systems", IEEE Transactions on Power Systems, 2016, vol. 31, no. 1, pp. 718-726.

[2] J. He, Y. W. Li, F. Blaabjerg, and X. Wang, "Active harmonic filtering using current-controlled, grid-connected DG units with closed-loop power control”, IEEE Transactions on Power Electronics, 2014, vol. 29, no. 2, pp. 642-653.

[3] B. Singh, A. Chandra, K. Al. Haddad, "Power Quality Problems and Mitigation Technique”, Hoboken, NJ, USA: Wiley Publishers, 2015.

[4] R. de Araujo Ribeiro, C. de Azevedo, and R. de Sousa, "A robust adaptive control strategy of active power filters for power-factor correction, harmonic compensation and balancing of nonlinear loads", IEEE Transactions on Power Electronics, 2012, vol. 27, no. 2, pp. 718-730.

[5] G. E. Valderrama, P. Mattavelli, A. M. Stankovic, "Reactive power and imbalance compensation using STATCOM with dissipativity-based control”, IEEE Transactions on Control Systems Technology, 2001, vol. 9, no. 5, pp. 718-727.

[6] CH. Sri Prakash, Kesava Rao, P. V. Satyaramesh, "A Critical Evaluation of Power Quality Features Using Unique Fundamental Reference Current Based Battery Integrated DSTATCOM", ARPN Journal of Engineering and Applied Sciences, 2018, vol. 13, no. 2, pp. 495-505.

[7] B. Singh and J. Solanki, "Load compensation for diesel generator-based isolated generation system employing DSTATCOM”, IEEE Transactions on Industry Applications, 2011, vol. 47, no. 1, pp. 238-244.

[8] Zaveri B, Zaveri N, "Simulation and analysis of control strategies for DSTATCOM", ACEEE International Journal on Control System and Instrumentation, 2010, vol. 1, no. 1, pp. 52-56.

[9] Mesbahi N, Ouari A, Omeiri A, "Reference current computation for three-level shunt active filter under distorted and unbalanced conditions", IEEE International Renewable and Sustainable Energy Conference (IRSEC), Morocco. 2013, pp. 343-347.

[10] Koteswara Rao U, Mishra K, and Ghosh A, "Control strategies for load compensation using instantaneous symmetrical component theory under different supply voltages", IEEE Transactions on Power Delivery, 2008, vol. 23 , no. 4 , pp. $2310-2317$.

[11] Metin Kesler, Engin Ozdemir, "Synchronous-Reference-Frame-Based Control Method for UPQC under Unbalanced and Distorted Load Conditions", IEEE Transactions on Industrial Electronics, 2011, vol. 58, no. 9, pp. 3967-3975.

[12] Herrera, R.S. Salmeron, P, "Instantaneous Reactive Power Theory: A Comparative Evaluation of Different Formulations", IEEE Transactions on Power Delivery, 2007, vol. 22, no. 1, pp. 595-604.

[13] C. Kumar, M. K. Mishra, "A multifunctional DSTATCOM operating under stiff source”, IEEE Transactions on Industrial Electronics, 2014, vol. 61, no. 7, pp. 3131-3136.

[14] Seon. Ju, P. Jin-Woo, C. IL-Yop, M. Seung-Il, K. Sang-Hee, and N. Soon-Ryul, "Power-sharing method of multiple distributed generators considering control modes and configurations of a microgrid", IEEE Transactions on Power Delivery, 2010, vol. 25, no. 3, pp. 2007-2016.

[15] G. Satyanarayana, K. Lakshmi Ganesh, "Tuning a Robust Performance of Adaptive Fuzzy-PI Driven DSTATCOM for Non-Linear Process Applications", Springer Lecture Notes in Computer Science International Swarm Evolutionary and Memetic Computing, SEMCCO Conference, 2015, pp. 8947: 523-533, Springer, Cham.

[16] R. Gupta, A. Ghosh, A. Joshi, "Performance comparison of VSC-based shunt and series compensators used for load voltage control in distribution systems", IEEE Transactions on Power Delivery, 2011, vol. 26, no. 1, pp. 268-278.

[17] Syed Ruman, Shail Hameed, "A Novel approach for design and analysis of voltage controlled DSTATCOM for power quality enhancement”, TELKOMNIKA (Telecommunication Computing, Electronics and Control), 2015, vol. 15 , no. 3, pp. 486-496.

[18] Ambarnath Banerji, Sujit K. Biswas, Bhim Singh, "DSTATCOM Control Algorithms: A Review", International Journal of Power Electronics and Drive System, 2012, vol. 2, no. 3, pp. 285-296.

[19] CH. Sri Prakash, Dr. Kesava Rao, Dr. O. Chandrasekhar, Dr. P. V. Satyaramesh, "A Fundamental Current Reference Control Strategy for DSTATCOM under Various Load Situations", International Journal of Electrical Engineering and Computer Science, 2017, vol. 7, no. 3, pp. 606-616. 